\title{
Only a statutory inquiry into the handling of Coronavirus will do
}

ollowing determined

lobbying by the Covid-19

Bereaved Families for Justice, a group of some 2,000 bereaved families, Boris Johnson in July promised an 'independent inquiry' into his Government's handling of the coronavirus pandemic 'at some point'.

He consistently maintains that now is not the time and will give no indication as to when will be the time beyond suggesting when the situation ends. Similarly he will say nothing about the form of the inquiry; calling it independent guarantees nothing.

The group believes that a Statutory inquiry should be set up immediately with a rapid review first phase. Here's why.

The Government under Article 2 of the ECHR needs to conduct a full investigation into all Covidrelated deaths, since there are so many issues of failures by the Government to protect the public. Coroners take the view that they cannot hold inquests to investigate national systemic issues and in practice are reluctant to investigate any Covid-19 deaths.

Under the Inquiries Act 2005 section one, 'A Minister may cause an inquiry to be held where... particular events have caused, or are capable of causing, public concern'. The Minister decides on the scope of the inquiry and its start date. Inquiries are held in public

\section{September}

29: Downing Street documents reveal plans for 'potential offshoring of asylum processing centres for those using clandestine entry routes to the UK.' Three specific countries (Moldova, Morocco and Papua New Guinea) are named as possible destinations for asylum processing centres. (subject to exceptions). Importantly the Chair of the inquiry can (s.21) require anyone to attend to testify (on oath), to produce documents and other evidence to the inquiry.

It is an offence punishable by imprisonment (s.35) during the course of the inquiry to distort or alter any evidence which is given or produced to the inquiry, to intentionally supress, destroy, alter or conceal a relevant document. This means that the sooner the inquiry (not necessarily the hearing) starts the sooner the integrity of the evidence is preserved.

The exercising of retrieving and compiling documentation and evidence for an inquiry commonly takes several years and generally hearings will not commence until the bulk of the evidence is available. So establishing an inquiry now would not mean the full hearings would commence immediately. It would however enable a minister or the Chair of the inquiry to make clear that all evidence should be retained.

Furthermore the Government has lost trust by several acts including the blind support of

\section{'Johnson agreed to meet the group of} families, then changed his mind, causing untold distress.'

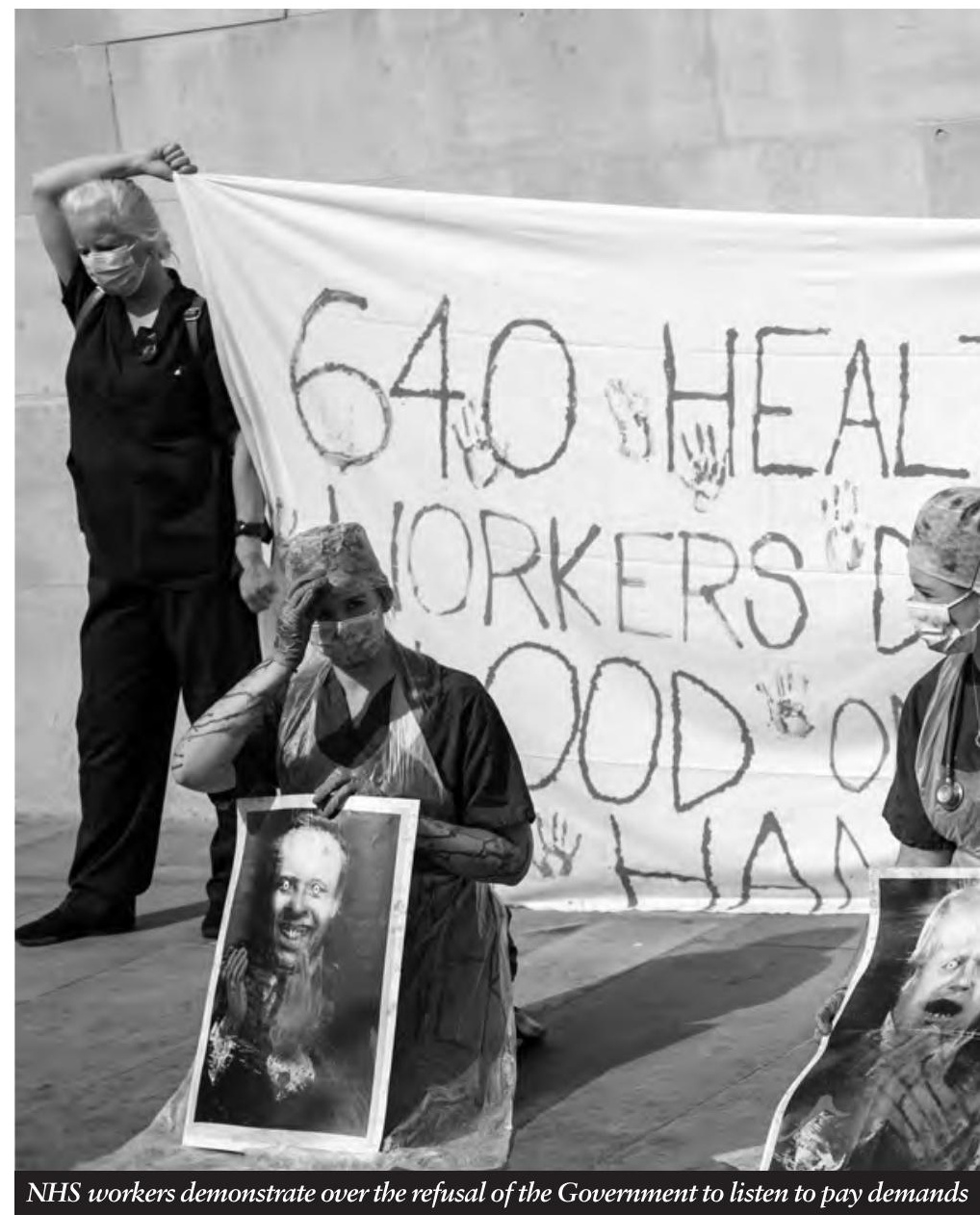

Dominic Cummings, the failure to provide PPE equipment to care homes (and hospitals), the failure to protect the vulnerable in care homes, setting up a revolving door between care homes and hospitals, failure of the track and trace system, treatment of the BAME communities and the delays in lockdown 1 and lockdown 2 .

Finally, if an inquiry was established now it could look at and make recommendations with regard to discrete issues - for example the management of the vaccine rollout. Such recommendations could save lives, either by pointing out governmental errors which could be corrected, or by setting out sound reasons for Government decisions and thereby increasing public confidence. Another example is the controversy around multiple allegations of impropriety in awarding government purchasing contracts.

\section{October}

1: Bar Council's open letter before the Government's annual spending review reveals some barristers are earning less than the minimum wage and that the justice system is at a 'tipping point' after decades of underfunding
1: Revealed that the Home Office contractors Serco moved dozens of asylum seekers involved in a Covid outbreak in Birmingham more than 120 miles despite an enforcement order saying they should remain in isolation for 14 days.
5: The family of Sakina Afrashabi, a disabled woman who died in Grenfell Tower, is suing the Government to force high-rise owners to make evacuation plans for every disabled resident.
6: Lord Reed, President of the Supreme Court, says a justice from a black, Asian or minority ethnic background should be appointed to its 12-person bench before he retires in six years time. 
